OPEN ACCESS

Edited by:

Francis Degache,

Motionlab, Switzerland

Reviewed by:

David Cristóbal Andrade, University of Antofagasta, Chile Tarak Driss,

Université Paris Nanterre, France

*Correspondence:

Lukas Zwingmann

Zwingmann.Lukas@gmail.com

Specialty section:

This article was submitted to

Exercise Physiology.

a section of the journal

Frontiers in Sports and Active Living

Received: 21 July 2021 Accepted: 04 November 2021 Published: 02 December 2021

Citation:

Zwingmann L, Zedler M, Kurzner S, Wahl P and Goldmann J-P (2021) How Fit Are Special Operations Police Officers? A Comparison With Elite Athletes From Olympic Disciplines. Front. Sports Act. Living 3:742655.

doi: 10.3389/fspor.2021.742655

\section{How Fit Are Special Operations Police Officers? A Comparison With Elite Athletes From Olympic Disciplines}

\author{
Lukas Zwingmann ${ }^{1,2 *}$, Marvin Zedler ${ }^{2,3}$, Stefan Kurzner ${ }^{4}$, Patrick Wahl ${ }^{1,2}$ and \\ Jan-Peter Goldmann ${ }^{2,3}$
}

${ }^{1}$ Department of Molecular and Cellular Sports Medicine, Institute of Cardiology and Sports Medicine, German Sport University Cologne, Cologne, Germany, ${ }^{2}$ The German Research Centre of Elite Sport Cologne, German Sport University Cologne, Cologne, Germany, ${ }^{3}$ Institute of Biomechanics and Orthopaedics, German Sport University Cologne, Cologne, Germany, ${ }^{4}$ Bureau for Education, Advanced Training, and Personnel Matters, North Rhine-Westphalia State Police, Selm, Germany

The diverse tasks of special operations police (SOP) units place high physical demands on every officer. Being fit for duty requires a wide range of motor abilities which must be trained regularly and in a structured manner. But SOP operators have to plan and manage large proportions of their training alone, which makes it difficult to control. Therefore, this study aimed to highlight strengths and deficits of the SOP operators' fitness by comparing them to elite athletes, and to define future training goals. Retrospective data of 189 male SOP operators were used, who completed several isometric strength tests, a graded exercise test to determine maximal oxygen uptake, and countermovement jumps to determine leg muscle power. On the basis of a literature search, performance data were then compared to a total of 3,028 elite male athletes from 36 Summer Olympic disciplines. Pooled means and standard deviations were calculated for each discipline and effect sizes were used to analyze their similarities and differences to the SOP unit. On average, SOP operators were taller, heavier, and stronger than elite athletes. But both the ability to convert this strength into explosive movement and aerobic power was significantly less developed. From this point of view, SOP operators should consider polarized endurance training to work efficiently on improving aerobic performance. In addition, regular plyometric training seems necessary to improve leg muscle power and agility.

Keywords: fitness profile, policing, SWAT, maximum oxygen uptake $\left(\mathrm{VO}_{2} \mathrm{max}\right)$, occupational health, physical training and conditioning, elite athletes, performance testing

\section{INTRODUCTION}

Special operations police (SOP) units play a central role in the fight against high-risk crime and are primarily deployed in situations that exceed the competences and capabilities of general police authorities. The daily physical demands of SOP operators can vary greatly by nature and are related to the tasks being completed. A survey in Australia and New Zealand showed that the most common task is the execution of high-risk warrants of arrest, followed by rural operations, high-risk 
personal protection, and counter-terrorism response (Irving et al., 2019). SOP units are regularly challenged by physical activities such as running up or down stairs, pulling, lifting, and carrying heavy objects, running or sprinting over a variety of distances, and negotiating obstacles (Silk et al., 2018; Marins et al., 2020).

Apparently, police officers must have a high level of physical fitness, above average for general police service, when applying for a SOP unit. The importance of adequate and regular training is reinforced by the fact that individuals with good aerobic and muscular power show a higher success rate in selection courses (Hunt et al., 2013) and are less likely to get injured (Orr et al., 2013, 2016). Nevertheless, it is still somewhat difficult both to classify the physical requirements for SOP operators and to give applicants concrete recommendations for daily training. This is because few studies exist which have outlined a comprehensive fitness profile of SOP units (Pryor et al., 2012; Strader et al., 2020). Other research has examined only aerobic performance, but not muscular strength, agility, or body composition (Sperlich et al., 2011; Maupin et al., 2018). Contrasting, the functional capability and physical demands of general police units have widely been evaluated, showing a great heterogeneity between departments and countries (Marins et al., 2019).

Additionally, little is known about the training practices of SOP units, partly because they are often kept secret and partly because police officers have to design large proportions of their training programs autonomously (Davis et al., 2016; Marins et al., 2020). Marins et al. (2020) recently showed that the physical training of Brazilian tactical operators is to $48 \%$ unsupervised, $61 \%$ self-planned, and 50\% unstructured, which is comparable to an earlier study by Davis et al. (2016) in the United States. Consequently, annual pass rates for SOP selection courses are highly variable, e.g., ranging from 18 to $70 \%$ in Australian special forces (Hunt et al., 2013). Therefore, accurately compiled performance standards and reference values to guide applicants and instructors might contribute to a more homogeneous selection process, less injuries, and thus to a more efficient use of human and financial resources.

Further, SOP units have to be fit and prepared for a variety of operations every day throughout the year. This requires not only the development of a wide range of motor abilities, but also a regular and structured training regimen. However, physical deficits are difficult to recognize because there are no internal references against which SOP operators can be measured. Using elite athletes as an external reference might allow to better classify and evaluate the metabolic and neuromuscular performance of SOP officers. Additionally, as much of the sporting activity is completed autonomously and takes place in leisure time as well, comparison to such individual or team athletes might be practical and easy to comprehend. Especially athletes from Olympic disciplines are widely studied and, therefore, training forms, volumes, and intensities can be derived from existing literature to optimize the SOP operators' daily physical preparation.

Accordingly, the purpose of this study is to provide a detailed fitness profile of a large cohort of German SOP operators with respect to anthropometry, aerobic performance, muscular strength, and vertical jump performance and to compare selected measures with those of elite athletes.

\section{METHODS}

\section{Participants}

Anonymized retrospective data (2017-2020) were analyzed from a total of 189 German police officers who successfully completed the SOP selection process of the North Rhine-Westphalia State Police. All participants were male and in both cardiovascular and musculoskeletal health. The average body mass and height were $83.1 \pm 7.1 \mathrm{~kg}$ and $182 \pm 6 \mathrm{~cm}$, respectively. To protect the identity of the police officers, no birth or age data were collected. However, the age of SOP candidates in Germany is usually between 25 and 35 years, as police officers have to resign from a SOP unit by the time they reach $\sim 45$ years (personal communication).

All participants were informed in detail about the examination procedures, techniques, and risks before signing the institutionally approved informed consent document. All procedures were approved by the Ethics Committee of the German Sport University Cologne under the number 051/2018 and were in accordance with the Declaration of Helsinki.

\section{Testing Procedures}

All tests were performed on the same day and in randomized order, except for the initial bioelectrical impedance analysis and a 15-minute warm-up on a motorized treadmill at a self-selected speed. Participants were given a 30 -min rest between the tests.

\section{Anthropometrics}

Body height was measured to the nearest $0.1 \mathrm{~cm}$ using a stadiometer (seca 274, seca GmbH \& Co KG, Hamburg, Germany). Body mass, fat mass, and muscle mass were measured in standing position to an accuracy of $0.05 \mathrm{~kg}$ using a phasesensitive 8-electrode bioelectrical impedance device (seca mBCA 515, seca GmbH \& Co KG, Hamburg, Germany).

\section{Muscle Strength}

A total of six isometric strength tests were performed to give a holistic picture of whole-body muscle strength. To ensure high practical relevance and generalizability, the tests have been adopted from real physical tasks frequently encountered on duty such as (overhead) lifting, carrying, and grabbing (Pryor et al., 2012; Marins et al., 2020). Participants were verbally motivated to push or pull on a stationary force transducer (EvalTech, BTE Technologies, Hanover, NH, USA) with maximal effort. During each trial, the participants were instructed to slowly build up force and hold for $5 \mathrm{~s}$ once they reached maximal force. A trial was considered valid upon visual inspection of the force-time plateau. Each participant completed three trials per test of which the best was included in the analysis. A minimum of 2 min rest was allowed between each trial to reduce the risk of muscular fatigue. Isometric strength was determined in $\mathrm{N}$ and calculated using a $5 \mathrm{~s}$ average of the force-time plateau. Figure 1 shows the corresponding test settings. 


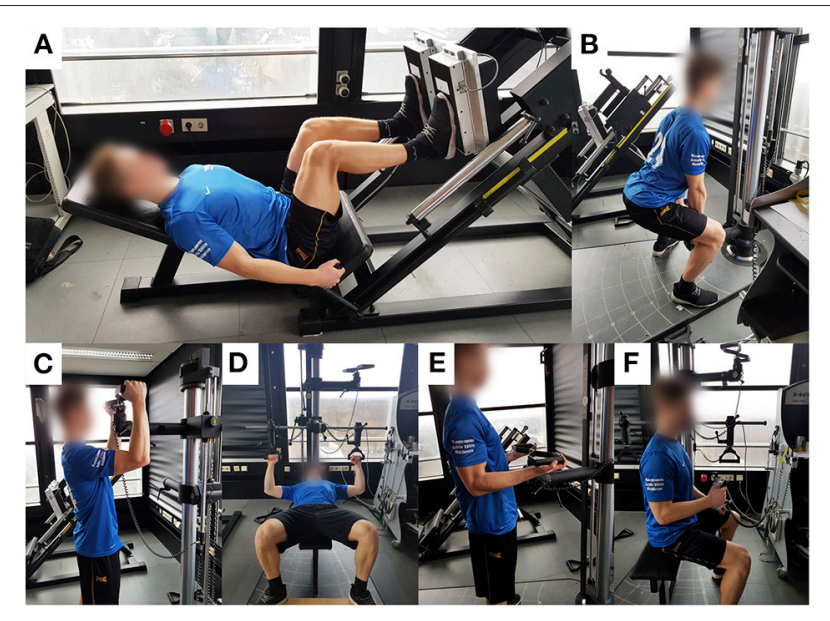

FIGURE 1 | Pictures of the isometric strength test settings. (A) Leg press; (B) Upright pull; (C) High lift; (D) Bench press; (E) Arm lift; (F) Hand grip strength.

\section{Leg Press}

The participants were placed in a leg press machine which was adjusted and fixed at a $90^{\circ}$ knee angle. A custommade force platform with strain gauges (Feinmechanische Entwicklungswerkstatt, German Sport University Cologne, Germany) was mounted onto the foot panel. The feet were positioned at hip width and in the middle of the panel.

\section{Upright Pull}

Participants were encouraged to pull on a force transducer (EvalTech, BTE Technologies, Hanover, USA) mounted at a height of $38 \mathrm{~cm}$. This force transducer was also used for the high lift, bench press, and arm lift. The following criteria regarding lifting technique had to be fulfilled: (1) Fixation of the spinal column in a neutral position, (2) positioning of the shoulders vertically above the line of action, (3) avoidance of flexion in the elbow joint or lifting the heel off the ground.

\section{High Lift}

Participants had to push vertically upwards on the force transducer mounted above shoulder height. To do this, they stood upright, legs extended, upper arms raised at $90^{\circ}$ anteversion, and elbow joints flexed at $90^{\circ}$. The heels were not allowed to be lifted from the ground for a valid attempt.

\section{Bench Press}

The participants lay with their backs on a bench and had to press on two separate handles mounted at a height and width at which the upper arms were abducted $90^{\circ}$ and the forearms positioned in vertical direction resulting in $90^{\circ}$ flexion of the elbow joints. The buttocks had to be in contact with the bench during each attempt.

\section{Arm Lift}

This test was performed in a standing position. The handles were set at a height at which the elbow joints were bent $90^{\circ}$ without shoulder anteversion. With the forearms in supination, the subjects again had to pull vertically upwards on the handles. For a valid test, the heels and shoulders were not allowed to be lifted.

\section{Hand Grip Strength}

Hand grip strength was measured in a sitting position for the dominant and non-dominant hand (Trailite, LiteXpress GmbH, Ahaus, Germany). The elbow joints were in $90^{\circ}$ flexion and the forearms in neutral position. For further analyses, the best trials of both hands were averaged.

\section{Vertical Jump Performance}

Each participant performed countermovement jumps (CMJ) without arm swing and hands placed on the hips. Jump height was defined as the highest out of five trials and calculated by mathematical integration of the force-time curve of the vertical ground reaction force (MATLAB, The MathWorks Inc., Natick, MA, USA), which was recorded by means of two force plates (Model 9281B, 1,000 Hz, Kistler Instrumente AG, Winterthur, Switzerland).

\section{Aerobic Performance}

An incremental exercise test on a motorized treadmill (saturn $\AA$, $\mathrm{h} / \mathrm{p} /$ cosmos sports \& medical GmbH, Nussdorf-Traunstein, Germany) was performed, which started at a speed of 2.4 $\mathrm{m} \cdot \mathrm{s}^{-1}$ and increased by $0.4 \mathrm{~m} \cdot \mathrm{s}^{-1}$ every $5 \mathrm{~min}$ until volitional exhaustion was reached. A $30 \mathrm{~s}$ rest was given between increments to allow capillary blood sampling from the earlobe. $\mathrm{VO}_{2}$ was measured using a stationary breath by breath gas analyser (MetaLyzer 3B, Cortex Biophysik GmbH, Leipzig, Germany), and $\mathrm{VO}_{2} \max$ was defined as the highest $30 \mathrm{~s}$ moving average. Blood lactate concentrations were measured using an enzymatic amperometric analyser (Biosen S-Line, EKF Diagnostics, Cardiff, Wales), plotted against running velocity, and fitted by a third order polynomial function. Afterward, anaerobic threshold (second lactate threshold, LT2) was calculated using the modified maximal deviation method (Zwingmann et al., 2019).

\section{Literature Search Search Strategies}

To classify the fitness profile of SOP operators in the context of elite sports, a literature search was conducted in PubMed and Google Scholar databases during a period from November 2020 to February 2021. As the methodology of studies conducting performance tests often considerably differs (especially with regard to strength tests), the literature search focused on the parameters body mass, body height, $\mathrm{VO}_{2} \max$, hand grip strength, and CMJ height. The search terms consisted of all current Summer Olympic disciplines, each of which was combined with one or more of the following terms using the Boolean operators AND and OR: fitness, physiological profile, aerobic capacity, aerobic power, $\mathrm{VO}_{2} \max$, grip strength, vertical jump, countermovement jump, CMJ. In addition, the reference lists of reviews and selected studies as well as the lists of similar 
articles provided by the databases were searched for further eligible literature.

\section{Selection Criteria and Data Extraction}

To ensure that the physical performance reported in the selected studies is consistent with the current level of elite athletes, only peer-reviewed publications from 2010 or later were included. They had to be written in English and available as full text. Additionally, information had to be provided in the manuscript that the athletes were adult males and performed their sport at professional level.

Information on at least one of the chosen performance parameters (mean, SD, sample size) and the methods used had to be provided. If the results were only presented graphically, mean $\pm \mathrm{SD}$ were extracted using a web-based plot digitizer (WebPlotDigitizer; https://automeris.io/WebPlotDigitizer/).

$\mathrm{VO}_{2}$ max had to be measured by means of an exhaustive graded exercise test using a gas analyser. The CMJ height had to be determined either by integrating the force-time curve of the vertical ground reaction force or by flight time. Hand grip strength had to be recorded isometrically and at least with the dominant hand.

If a parameter was determined in multiple studies, the means and SD for each sport were combined using the formulas proposed by Higgins et al. (2020):

$$
\begin{aligned}
\text { Mean } & =\frac{N_{1} M_{1}+N_{2} M_{2}}{N_{1}+N_{2}} \\
S D & =\sqrt{\frac{\left(N_{1}-1\right) S D_{1}^{2}+\left(N_{2}-1\right) S D_{2}^{2}+\frac{N_{1} N_{2}}{N_{1}+N_{2}}\left(M_{1}^{2}+M_{2}^{2}-2 M_{1} M_{2}\right)}{N_{1}+N_{2}-1}}
\end{aligned}
$$

where $\mathrm{N}_{1}, \mathrm{~N}_{2}$ are the sample sizes, $\mathrm{SD}_{1}, \mathrm{SD}_{2}$ are the standard deviations, and $M_{1}, M_{2}$ are the means of the two studies to be combined. For more than two studies, the formulas were applied stepwise. Detailed information about the studies included are provided as Supplementary Material.

\section{Statistical Analysis}

Descriptive statistics of the data are presented as means \pm SD. Coefficients of variation $(\mathrm{CV})$ were calculated to better describe the variability of the parameters recorded. To compare the outcomes between sports and the SOP unit, adjusted effect sizes (d) were calculated as proposed by Hedges and Olkin (1985). $d$ smaller 0.35 was considered a trivial effect, $d$ between 0.35 and 0.8 a small effect, $d$ between 0.8 and 1.5 a moderate effect, and $d$ greater 1.5 a strong effect (Bernards et al., 2017).

\section{RESULTS}

The anthropometric and performance data of the SOP unit are presented in Table 1.

As a result of the literature search, a total of 138 studies met the criteria for inclusion in the analyses. These studies reported performance data from 3,028 professional male athletes participating in one of 36 Summer Olympic sports or disciplines. No studies could be included for the following Summer Olympic sports or disciplines due to either inappropriate methodology or sampling: Archery, Decathlon, Discus Throw, Javelin Throw, Shot Put, Long Jump, Pole Vault, Triple Jump, Breaking, Track Cycling, Diving, Equestrian, Skateboarding, and Trampoline.

For body mass and body height, 2,889 and 2,694 athletes from 35 and 34 sports were included. Rankings of the combined means \pm SD for each cohort and parameter (including the SOP unit) are shown in Figure 2. The resulting differences between each sport and the SOP unit, as well as the effect sizes are provided in Table 2. The SOP unit was among the 10 heaviest and tallest cohorts analyzed. Following the calculated effect sizes, body mass of the SOP unit was most similar to judoka, water polo players and rowers, with $d$ between -0.18 and 0.22. Marathon runners were the lightest cohort (60.4 \pm $4.6 \mathrm{~kg}, d=-3.32$ ), rugby players were the heaviest cohort analyzed $(96.4 \pm 15.4 \mathrm{~kg}, d=1.16)$. Trivial effect sizes regarding body height were found in seven cohorts ranging from-0.29 to 0.28 , including sports like football, high jumping, swimming, and rugby. Gymnasts were the smallest $(166.8 \pm 7.5 \mathrm{~cm}, d$ $=-2.46)$, basketball players were the tallest cohort analyzed $(196.9 \pm 7.9 \mathrm{~cm}, d=2,09)$.

The number of athletes included in the analyses of $\mathrm{VO}_{2} \mathrm{max}$, hand grip strength, and CMJ was 1,599, 815, and 1,421, each of whom participated in one of 31,23 , and 23 sports or disciplines, respectively. Rankings of the combined means \pm SD for each

cohort and parameter (including the SOP unit) are shown in Figure 3. The resulting differences between each sport and the SOP unit, as well as the effect sizes are provided in Table 3. With $52.4 \pm 4.1 \mathrm{~mL} \cdot \mathrm{min}^{-1} \cdot \mathrm{kg}^{-1}, \mathrm{VO}_{2}$ max of the SOP unit was among the eight weakest cohorts analyzed. The highest values were found in middle- to long-distance runners $(72.9 \pm 6.2$ $\left.\mathrm{mL} \cdot \mathrm{min}^{-1} \cdot \mathrm{kg}^{-1}, d=4.20\right)$, the lowest values were found in surfers $\left(41.6 \pm 5.0 \mathrm{~mL} \cdot \mathrm{min}^{-1} \cdot \mathrm{kg}^{-1}, d=-2.57\right)$. The $\mathrm{VO}_{2} \max$ of SOP operators was most similar to that of rugby, baseball, volleyball players, judoka, and sport climbers ( $d$ ranging from -0.06 to 0.33 ).

Hand grip strength showed less variability between cohorts than the other parameters analyzed. The SOP unit was above average $(549 \pm 94 \mathrm{~N})$ and showed low effect sizes against 10 sports ( $d$ ranging from -0.31 to 0.33). Sport climbers showed the highest grip strength $(658 \pm 116 \mathrm{~N}, d=1.12)$, volleyball players the lowest $(408 \pm 31 \mathrm{~N}, d=-1.60)$.

CMJ height of the SOP unit was among the five lowest cohorts analyzed $(36.8 \pm 5.1 \mathrm{~cm})$. The biggest difference to the SOP unit was shown by the sprint runners who jumped about $14.33 \mathrm{~cm}$ higher on average $(d=2.45)$. Effect sizes were trivial in comparison to middle- and long-distance runners, wrestlers, water polo players, swimmers, and fencers ( $d$ ranging from -3.00 to 3.00 ). 
TABLE 1 | Anthropometric and performance test results of German special operations police operators.

\begin{tabular}{|c|c|c|c|c|c|}
\hline Parameter & $\mathbf{N}$ & Mean \pm SD & CV (\%) & $\begin{array}{l}95 \% \text { Confidence } \\
\text { Interval }\end{array}$ & Range \\
\hline \multicolumn{6}{|l|}{ Anthropometrics } \\
\hline Body height (cm) & 177 & $182.4 \pm 6.0$ & 3.3 & $181.5-183.3$ & $169.5-202.5$ \\
\hline Fat mass (kg) & 177 & $11.0 \pm 3.6$ & 32.7 & $10.5-11.5$ & $2.3-24.4$ \\
\hline Lean mass (\%) & 177 & $86.8 \pm 3.6$ & 4.1 & 86.3-87.4 & $79.5-97.0$ \\
\hline Total muscle mass $(\mathrm{kg})$ & 177 & $35.9 \pm 2.9$ & 8.1 & $35.5-36.3$ & $30.1-43.6$ \\
\hline Muscle mass torso (kg) & 177 & $16.8 \pm 1.4$ & 8.3 & $16.6-17.0$ & $13.2-20.5$ \\
\hline Muscle mass lower limbs (kg) & 177 & $14.0 \pm 1.2$ & 8.6 & $13.8-14.2$ & $11.2-16.9$ \\
\hline Muscle mass upper limbs (kg) & 177 & $5.1 \pm 0.5$ & 9.8 & $5.0-5.2$ & $4.0-6.6$ \\
\hline Bench press $(\mathrm{N})$ & 177 & $1,128 \pm 164$ & 14.6 & $1,104-1,152$ & $789-1,579$ \\
\hline Arm lift (N) & 177 & $549 \pm 75$ & 13.7 & $538-560$ & 336-873 \\
\hline Hand grip strength $(\mathrm{N})$ & 177 & $549 \pm 94$ & 17.0 & $535-563$ & $308-831$ \\
\hline \multicolumn{6}{|l|}{ Vertical jump performance } \\
\hline CMJ (cm) & 177 & $36.8 \pm 5.1$ & 13.9 & $36.0-37.6$ & $22.6-51.2$ \\
\hline \multicolumn{6}{|l|}{ Aerobic power } \\
\hline $\mathrm{VO}_{2} \max \left(\mathrm{L} \cdot \mathrm{min}^{-1}\right)$ & 189 & $4.35 \pm 0.44$ & 10.2 & $4.29-4.41$ & $3.13-5.70$ \\
\hline $\mathrm{VO}_{2} \max \left(\mathrm{mL} \cdot \mathrm{min}^{-1} \cdot \mathrm{kg}^{-1}\right)$ & 189 & $52.4 \pm 4.1$ & 7.8 & $51.8-53.0$ & $41.0-66.5$ \\
\hline LT2 $\left(m \cdot s^{-1}\right)$ & 183 & $3.57 \pm 0.22$ & 5.6 & $3.54-3.60$ & $2.84-4.28$ \\
\hline
\end{tabular}

CV, Coefficient of Variation; CMJ, Countermovement jump; LT2, Second lactate threshold; $\mathrm{VO}_{2}$ max, Maximum oxygen uptake.

\section{DISCUSSION}

The primary purpose of this study was to describe the physical characteristics and performance of German SOP operators and to compare selected parameters with those of professional athletes.

In terms of body anthropometry, SOP operators were shown to be heavier and taller than the average of all cohorts. With $182.4 \pm 6.0 \mathrm{~cm}$, body height was most similar to that of football players, high jumpers, swimmers, or rugby players, but smaller than that of basketball, volleyball, handball players, or rowers. In some sports, such as those previously mentioned, a tall body height offers several advantages in terms of athletic performance (Tsoukos et al., 2019; Zarić et al., 2020). The importance of body height in the police profession has been subject to a controversial debate for decades. Internationally, a wide range of minimum height requirements exist as a selection criterion for police departments, varying from $152 \mathrm{~cm}$ in Belgium to $170 \mathrm{~cm}$ in Greece (Kirchengast, 2010). In the German state of North Rhine-Westphalia, this limit is currently $163 \mathrm{~cm}$ for both men and women (Ministry of the Interior of North Rhine-Westphalia, 2021). In some countries, such minimum requirements have been abolished because of their discriminatory nature and the lack of scientific evidence (Anderson et al., 2001; Kirchengast, 2010). To date, a few studies have found a weak relationship between body height and occupational task performance (Orr et al., 2018; Zwingmann et al., 2021b). In the study of Orr et al. (2018), taller participants tended to be more successful on the Australian Specialist Selection Course. Participants employed for the specialist unit averaged $183.8 \pm 4.6 \mathrm{~cm}$, which is similar to the average body height found in the present study. Consequently, body height appears to be a non-negligible factor in the police profession, similar to many Olympic sports reported in the present study. According to earlier research, however, the body height of SOP operators does not differ significantly from male officers of general police authorities in western countries (Leischik et al., 2015; Dawes et al., 2017).

Since increasing body height is accompanied by increasing body mass, it is not surprising that 8 of the 10 tallest cohorts analyzed here are also among the 10 heaviest cohorts, including the SOP unit. With trivial effect sizes, body mass of SOP operators was most similar to that of rowers, water polo players, and judokas. Since elite athletes "have body sizes and compositions that closely match the specific constraints of their disciplines" (Haugen et al., 2018), this similarity could mainly come from the fact that in all these sports a large absolute strength and power output is crucial during physical contact with opponents or to accelerate heavy objects, such as a skull. Body mass, especially lean body mass, and a mesomorphic somatotype have not only been shown to positively correlate with power output in rowers and 

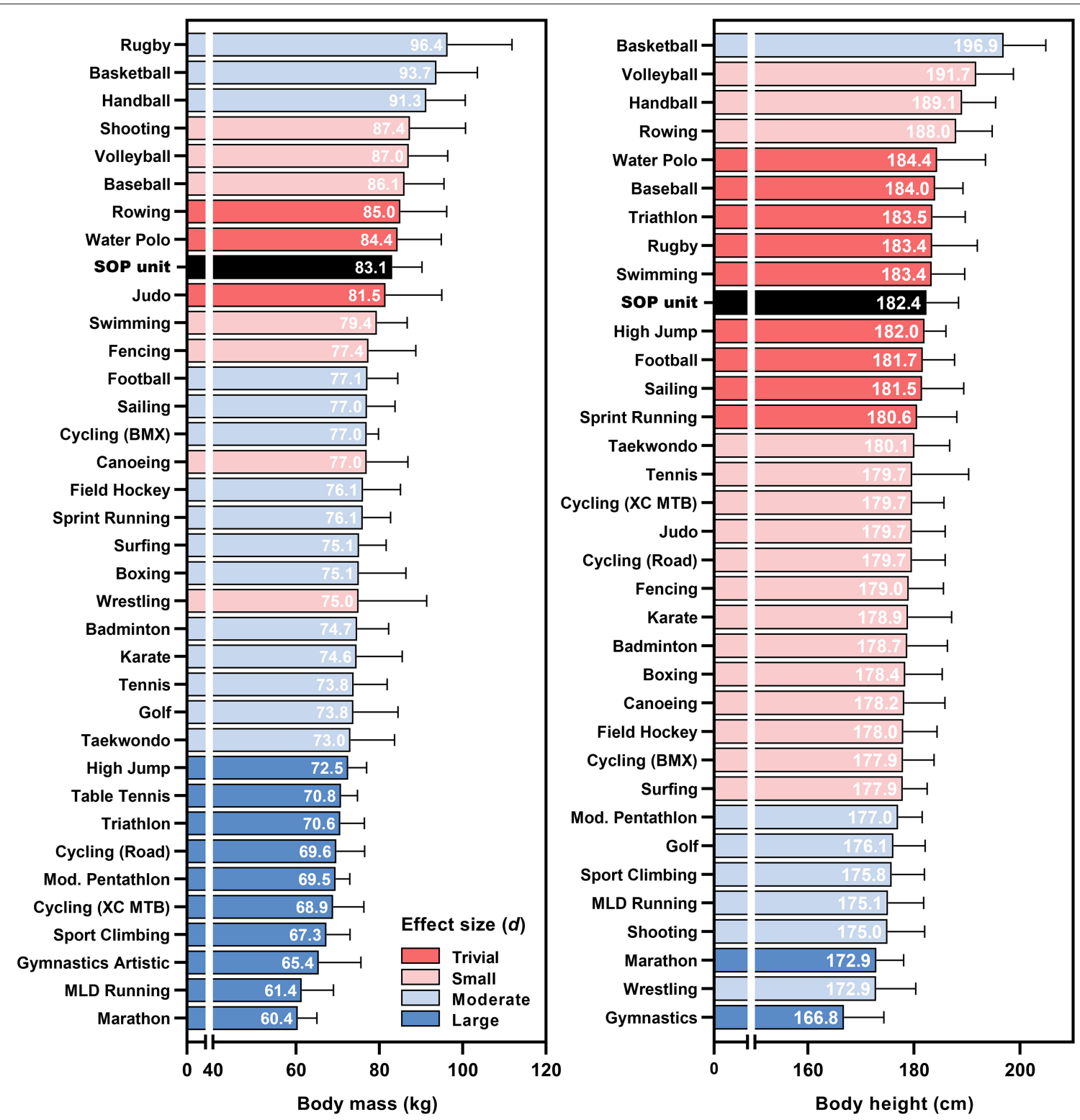

FIGURE 2 | Average body mass and height of elite athletes from Summer Olympic disciplines and the Special Operations Police unit (SOP unit), sorted by size. The color scale illustrates the effect size of each discipline compared to the SOP unit. BMX, Bicycle motocross; MLD, Middle- and long distance; XC MTB, Cross-country mountain bike.

judokas (Nevill et al., 2010; Lewandowska et al., 2011), but also with intensive policing activities, such as heavy lifting, dragging, or carrying (Vanderburgh, 2008; Zwingmann et al., 2021b). Contrary, increased body mass is associated with impaired endurance performance and increased energy expenditure (Vanderburgh, 2008; Zwingmann et al., 2021a,b). Therefore, and with respect to the varying physical demands of SOP units, it might not be a maximum but an optimum body size that is decisive for operational capability, roughly ranging from 181 to $184 \mathrm{~cm}$ and 81 to $85 \mathrm{~kg}$ when compared to elite athletes.

In this context, the contribution of fat and muscle mass on total body mass needs to be considered as well. Using dualenergy X-ray absorptiometry, these anthropometric traits have been shown to average $10.9 \mathrm{~kg}(13.9 \%)$ and $64.6 \mathrm{~kg}(84.9 \%)$, respectively, in a male athletic population (Santos et al., 2014). The SOP operators' average fat and lean mass were $11.0 \mathrm{~kg}$ $(13.1 \%)$ and $72.1 \mathrm{~kg}(86.8 \%)$. Despite a high variability of fat mass $(\mathrm{CV}=32.7 \%)$, this indicates their athletic physique and an above-average muscle mass. Santos et al. (2014) found the greatest lean mass in handball $(69.2 \mathrm{~kg}, 82.7 \%)$ and basketball players $(68.5 \mathrm{~kg}, 83.6 \%)$. In rowers, wrestlers/judokas, and other combat sports athletes, lean mass was $65.4 \mathrm{~kg}(83.3 \%), 61.2 \mathrm{~kg}$ (85.5\%), and $59.9 \mathrm{~kg}(85.2 \%)$, respectively. But it must be noted that given differences to the present study might partially be due to a wider range of the participants' age (16-45 years), smaller body height, and different measurement methods. 
TABLE 2 | Number of athletes included per sport, Coefficient of Variation (CV) within sport, difference between the mean of each sport and the special operations police unit, and effect size (d) for body mass and body height.

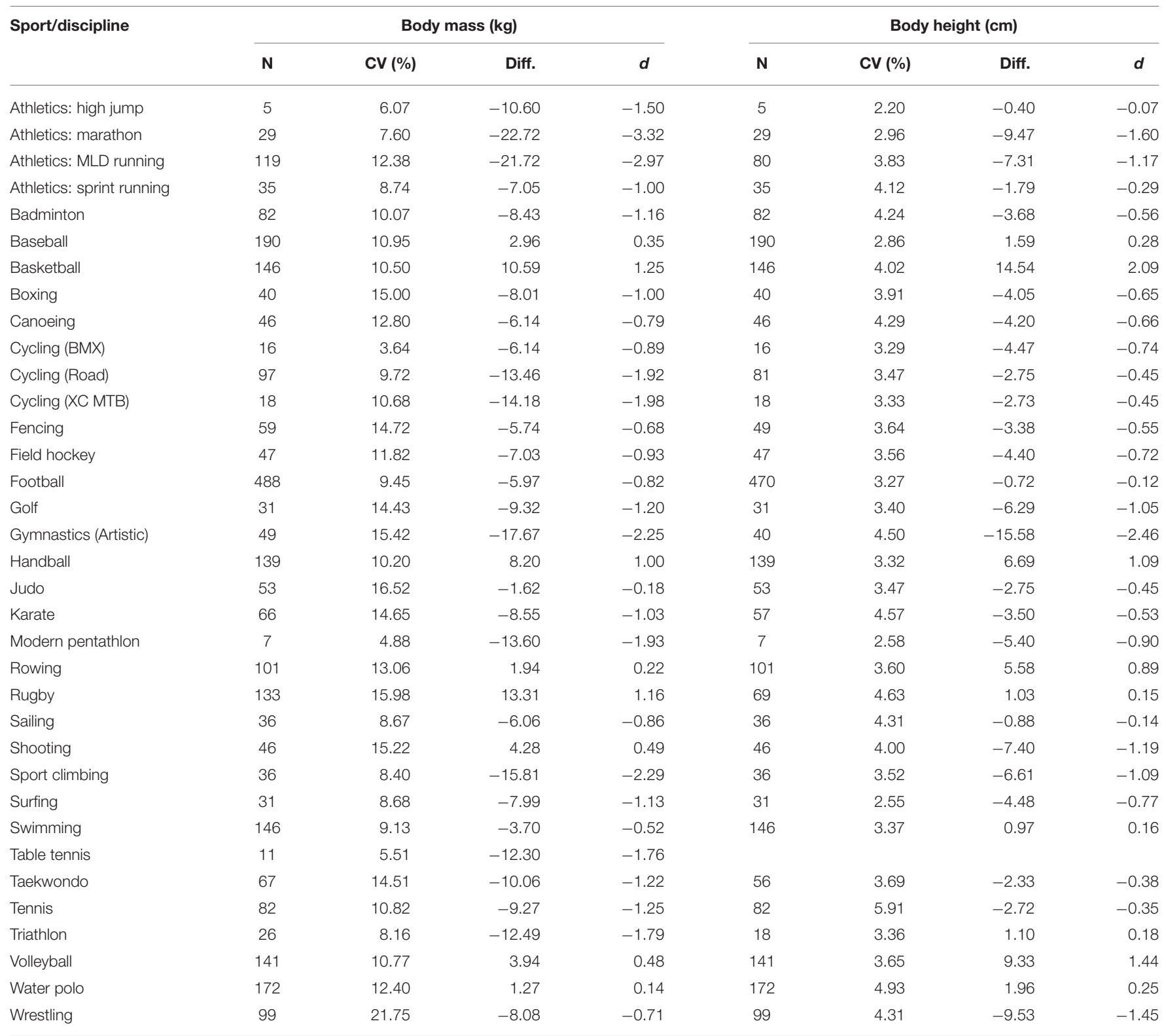

BMX, Bicycle motocross; MLD, Middle- and long-distance; XC MTB, Cross-country mountain bike.

Measures of muscle strength are somewhat difficult to compare with other studies, because the type of muscle work (concentric dynamic, isokinetic, isometric) as well as the joint angles chosen greatly influence their outcomes. Nevertheless, for instance, the bench press one repetition maximum has been shown to average $88 \pm 14$ to $102 \pm 13 \mathrm{~kg}$ in elite basketball players (Ben Abdelkrim et al., 2010; Balsalobre-Fernández et al., 2014), $89 \pm 19 \mathrm{~kg}$ in karate athletes (Loturco et al., 2014), $91 \pm$ 22 to $105 \pm 18 \mathrm{~kg}$ in canoeists (Hamano et al., 2015), and 145 \pm 5 to $164 \pm 5 \mathrm{~kg}$ in judokas (Drid et al., 2015). Loturco et al. (2016) demonstrated a bench and leg press isometric strength of $\sim 1,018 \pm 26$ and 2,610 $\pm 951 \mathrm{~N}$, respectively, in elite boxers using comparable joint angles as in the present study. Hence, with $1,128 \pm 164$ and $2,580 \pm 456 \mathrm{~N}$, bench and leg press isometric strength of SOP operators was equivalent to that of combat sports athletes, although no eligible studies exist to provide information on other sports.

One strength parameter that has been evaluated more frequently under comparable test conditions is hand grip strength. In many movement patterns, such as throwing or hitting, the hands represent the end of a kinetic chain through which a sum of muscular forces and resultant joint moments is transferred to an external sporting device or opponent. The significance of hand grip strength as a 

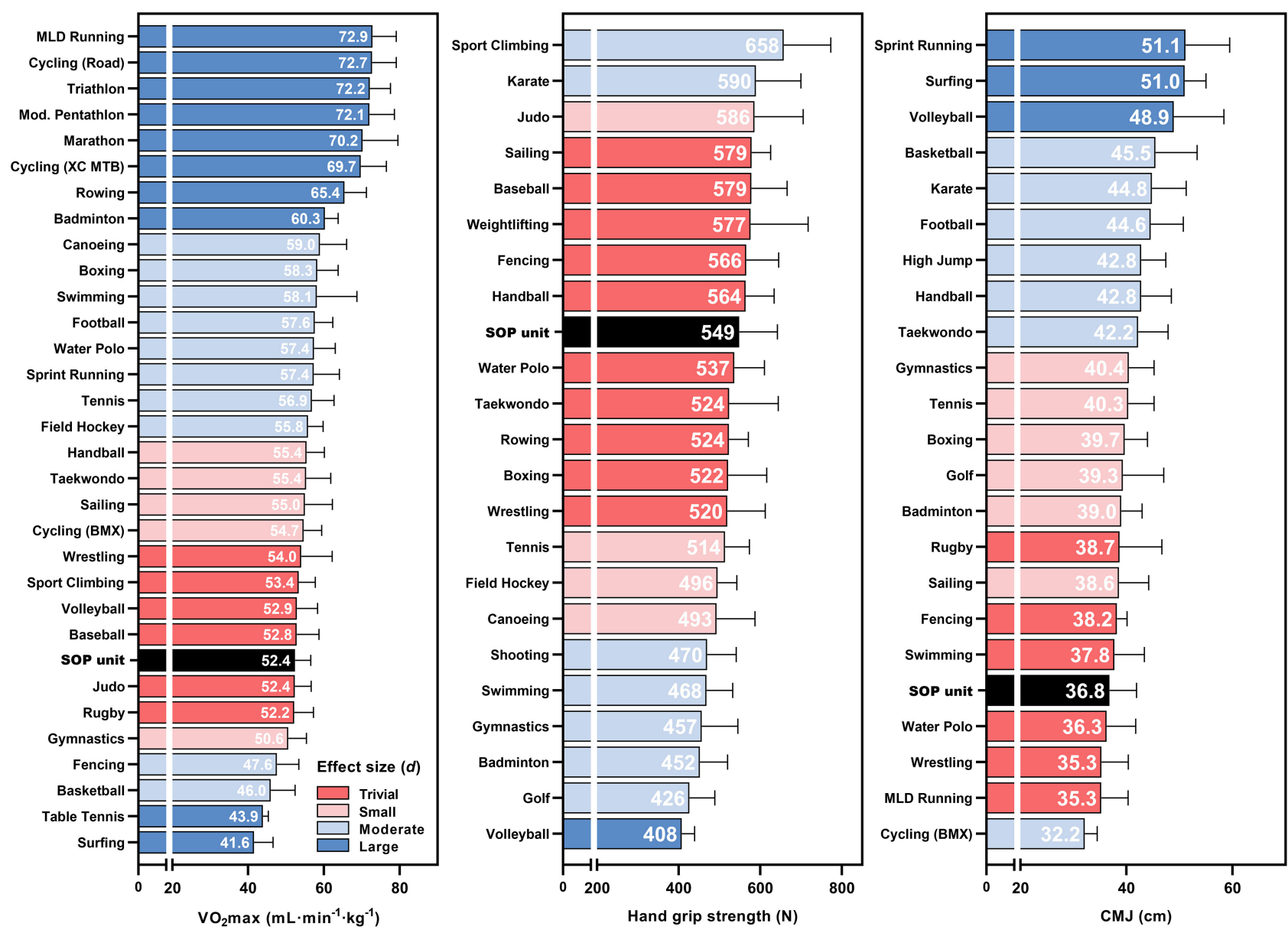

FIGURE 3 | Average maximum oxygen uptake $\left(\mathrm{VO}_{2} \mathrm{max}\right)$, hand grip strength, and countermovement jump height (CMJ) of elite athletes from Summer Olympic disciplines and the Special Operations Police unit (SOP unit), sorted by size. The color scale illustrates the effect size of each discipline compared to the SOP unit. BMX, Bicycle motocross; MLD, Middle- and long distance; XC MTB, Cross-country mountain bike.

limiting determinant of movement performance has repeatedly been demonstrated in sports such as climbing, baseball, or wrestling (Cronin et al., 2017). In the case of SOP units, fighting techniques, climbing tasks, and fast-roping from helicopters are activities that require a certain degree of hand grip strength as well. Further, hand grip strength is a weak but significant correlate of marksmanship with firearms (Copay and Charles, 2001). Although the influence of specific grip strength training on athletic performance is not welldocumented, it appears that grip strength is a covariate of overall muscle strength in a variety of sports and, therefore, positively affected by regular whole-body resistance training (Cronin et al., 2017).

In this study, hand grip strength values ranged from $408 \pm$ $31 \mathrm{~N}$ (volleyball players) to $658 \pm 115 \mathrm{~N}$ (sport climbers). With $549 \pm 94 \mathrm{~N}$, the SOP unit was among the 10 strongest cohorts and most similar to water polo players, handball players, and fencers, with a difference of $<20 \mathrm{~N}$. But effect sizes were also trivial compared to wrestlers, boxers, rowers, taekwondo athletes, weightlifters, baseball players, and sailors. These similarities seem plausible primarily because all of these Olympic disciplines involve an external sporting device or physical contact with opponents. As a limitation, however, it needs to be mentioned that in some cohorts either very small samples were examined or a high coefficient of variation led to small effect sizes (Table 3).

Overall, the shown strength test results indicate that a large proportion of the SOP operators' athletic training consists of heavy resistance exercises, which is in line with previous publications (Pryor et al., 2012; Davis et al., 2016; Marins et al., 2020). Contrasting, CMJ height was among the five worst performing cohorts, indicating a certain training deficit regarding leg muscle power. CMJ height of SOP operators was most similar to swimmers and Water Polo players. While the upper extremities are predominantly performance-limiting in such aquatic sports, the need for high dynamic leg power and agility in many policing activities seems intuitive and has frequently been demonstrated (Mala et al., 2015; Moreno et al., 2019). Regular plyometric and sprint training is known to improve such motor abilities (Markovic et al., 2007), which is emphasized in the present study by the fact that sprint 
TABLE 3 | Number of athletes included per sport, Coefficient of Variation (CV) within sport, difference between the mean of each sport and the special operations police unit, and effect size (d) for maximum oxygen uptake $\left(\mathrm{VO}_{2} \mathrm{max}\right)$, hand grip strength and countermovement jump height (CMJ).

\begin{tabular}{|c|c|c|c|c|c|c|c|c|c|c|c|c|}
\hline Sport/discipline & \multicolumn{4}{|c|}{$\mathrm{VO}_{2} \max \left(\mathrm{mL} \cdot \mathrm{min}^{-1} \cdot \mathrm{kg}^{-1}\right)$} & \multicolumn{4}{|c|}{ Hand grip strength (N) } & \multicolumn{4}{|c|}{ CMJ (cm) } \\
\hline Athletics: marathon & 29 & 13.25 & 17.84 & 3.50 & & & & & & & & \\
\hline Athletics: MLD running & 85 & 8.56 & 20.46 & 4.20 & & & & & 34 & 14.33 & -1.55 & -0.30 \\
\hline Athletics: sprint running & 24 & 11.72 & 4.95 & 1.11 & & & & & 41 & 16.29 & 14.33 & 2.45 \\
\hline Basketball & 69 & 13.96 & -6.41 & -1.32 & & & & & 146 & 17.22 & 8.67 & 1.33 \\
\hline Boxing & 30 & 9.44 & 5.86 & 1.35 & 10 & 18.10 & -27.29 & -0.29 & 20 & 10.78 & 2.89 & 0.57 \\
\hline Canoeing & 65 & 11.87 & 6.58 & 1.31 & 23 & 19.00 & -55.60 & -0.59 & & & & \\
\hline Cycling (BMX) & 6 & 8.59 & 2.30 & 0.56 & & & & & 10 & 7.25 & -4.65 & -0.93 \\
\hline Cycling (Road) & 97 & 8.73 & 20.32 & 4.07 & & & & & & & & \\
\hline Football & 407 & 8.25 & 5.19 & 1.14 & & & & & 448 & 13.85 & 7.76 & 1.32 \\
\hline Golf & & & & & 18 & 14.65 & -122.71 & -1.33 & 23 & 19.56 & 2.52 & 0.46 \\
\hline Gymnastics (Artistic) & 11 & 9.49 & -1.80 & -0.43 & 19 & 19.31 & -92.01 & -0.98 & 38 & 11.72 & 3.64 & 0.72 \\
\hline Handball & 38 & 8.50 & 3.02 & 0.72 & 32 & 12.35 & 15.22 & 0.17 & 107 & 13.23 & 5.99 & 1.12 \\
\hline Judo & 10 & 8.16 & -0.05 & -0.01 & 53 & 20.36 & 37.05 & 0.37 & & & & \\
\hline Karate & & & & & 26 & 18.65 & 40.65 & 0.42 & 48 & 14.39 & 8.02 & 1.48 \\
\hline Modern pentathlon & 7 & 9.13 & 19.65 & 4.66 & & & & & & & & \\
\hline Rowing & 86 & 8.88 & 13.02 & 2.76 & 27 & 9.05 & -25.44 & -0.28 & & & & \\
\hline Rugby & 18 & 9.70 & -0.25 & -0.06 & & & & & 108 & 20.56 & 1.91 & 0.30 \\
\hline Sailing & 36 & 13.19 & 2.58 & 0.54 & 21 & 8.04 & 30.08 & 0.33 & 21 & 14.51 & 1.80 & 0.35 \\
\hline Triathlon & 26 & 7.54 & 19.75 & 4.60 & & & & & & & & \\
\hline Volleyball & 64 & 10.33 & 0.48 & 0.11 & 30 & 7.62 & -141.04 & -1.60 & 90 & 19.32 & 12.12 & 1.76 \\
\hline Water polo & 8 & 9.76 & 5.00 & 1.20 & 107 & 13.74 & -12.20 & -0.14 & 57 & 15.12 & -0.55 & -0.11 \\
\hline Weightlifting & & & & & 25 & 24.46 & 27.63 & 0.27 & & & & \\
\hline Wrestling & 28 & 15.19 & 1.60 & 0.33 & 71 & 17.80 & -29.32 & -0.31 & 46 & 14.32 & -1.53 & -0.30 \\
\hline
\end{tabular}

BMX, Bicycle motocross; MLD, Middle- and long-distance; XC MTB, Cross-country mountain bike.

runners showed the best CMJ performance, followed by sports like volleyball and basketball. Therefore, a higher amount of plyometric and sprint training, as performed by sprinters or volleyball players (Haugen et al., 2019; Silva et al., 2019), should be considered for SOP training programs.

Aerobic power is another physical characteristic that is classified as crucial in police forces. Studies show that a high $\mathrm{VO}_{2}$ max positively affects operational task performance (Sperlich et al., 2011; Hunt et al., 2013; Zwingmann et al., 2021b) as well as injury prevalence (Orr et al., 2013). In competitive sports, it is believed to allow for improved recovery (Tomlin and Wenger, 2001) and to be an important requirement for gains in training volume and intensity. In men, $\mathrm{VO}_{2}$ max can reach very different magnitudes. Average values in healthy European males are highly variable and range from 25 to 51 $\mathrm{mL} \cdot \mathrm{min}^{-1} \cdot \mathrm{kg}^{-1}$, depending on age and physical activity (Van Der Steeg and Takken, 2021; Wagner et al., 2021). Contrarily, absolute and relative values in elite athletes can reach $7 \mathrm{~L} \cdot \mathrm{min}^{-1}$ and $85 \mathrm{~mL} \cdot \mathrm{min}^{-1} \cdot \mathrm{kg}^{-1}$ or higher (Haugen et al., 2018). In this study, relative $\mathrm{VO}_{2} \max$ in most cohorts was between 50 
and $60 \mathrm{~mL} \cdot \mathrm{min}^{-1} \cdot \mathrm{kg}^{-1}$, including the SOP unit $(52.4 \pm 4.1$ $\left.\mathrm{mL} \cdot \mathrm{min}^{-1} \cdot \mathrm{kg}^{-1}\right)$. Especially team, racket, and combat sports fall into this range, which are often characterized as sports with intermittent metabolic demands and frequent changes of direction (Chaabène et al., 2015; Fernandez-Fernandez et al., 2015; Peña et al., 2018). Overall, however, SOP operators were among the 10 worst performing cohorts analyzed here. With a trivial effect size, they were most similar to rugby, baseball, volleyball players, wrestlers, sport climbers, and judokas. It is notable that four of these six sports as well as the SOP unit were also among the 10 heaviest cohorts, illustrating the general body mass penalty of aerobic fitness tests against heavier individuals (Vanderburgh, 2008). However, consistent with previous research (Pryor et al., 2012), it shows that the potential in the development of $\mathrm{VO}_{2} \mathrm{max}$ is not yet fully utilized by SOP units. Although police officers frequently report a high proportion of regular endurance training (Davis et al., 2016; Irving et al., 2019; Marins et al., 2020), the training regimen might not yet be as effective or efficient as in most Olympic sports. On the other hand, it is questionable whether SOP operators can even achieve a comparable training volume and aerobic power like elite athletes who practice full-time and are able focus significantly more on performance optimization. Nevertheless, other studies on specialist forces revealed high $\mathrm{VO}_{2}$ max values of $57.4 \pm$ 4.2 (Sperlich et al., 2011) and $55.0 \pm 5.2 \mathrm{~mL} \cdot \mathrm{min}^{-1} \cdot \mathrm{kg}^{-1}$ (Simpson et al., 2017). Therefore, polarized endurance training, as performed by middle- and long-distance runners and which includes regular high-intensity bouts (Rosenblat et al., 2019), could probably contribute to a more efficient development of endurance performance.

\section{Limitations}

Both the results of the present study and their interpretation are limited to the publications that were available during the literature search. To be included, the publications had to meet several criteria. But at some point, particularly the methods used for CMJ determination often differed to such an extent that given variances must partly be attributed to this issue. For instance, there is no rational explanation for the fact that surfers showed a better CMJ performance than elite volleyball players, basketball players, or fencers. Sample sizes could also have had a significant impact on the results. Further, a graded exercise test with increments of $5 \mathrm{~min}$ duration was used to allow the determination of lactate thresholds. With regard to a previous study, this protocol might have had a small impact on the determination of $\mathrm{VO}_{2} \max$ (Wahl et al., 2018). However, the analyses show clear trends in the physical fitness of SOP operators that can be considered to design optimized training programs.

\section{CONCLUSION}

In summary, SOP operators are on average heavier, taller, and stronger compared to elite athletes. But both the ability to convert this strength into explosive movement and aerobic power is significantly less developed than in most elite athletes, although SOP operators rate the importance of aerobic and muscle power as equally important as muscle strength and regularly train these physical components accordingly. Thus, the weaknesses shown here might primary be a consequence of unstructured training methods. Consequently, a frequently supervised training regimen that is aligned with those of professional athletes might lead to a more balanced development of motor abilities, in line with the occupational requirements of SOP operators described in the literature. In the future, detailed training evaluations could help further differentiate strengths and weaknesses in the fitness of SOP operators and design purposeful training interventions. Measurements of the rate of force development could improve knowledge about SOP operators' muscle power, particularly that of the upper extremities.

\section{DATA AVAILABILITY STATEMENT}

The data that support the findings of this research are available from the corresponding author upon reasonable request.

\section{ETHICS STATEMENT}

The studies involving human participants were reviewed and approved by Ethics Committee of the German Sport University Cologne. The patients/participants provided their written informed consent to participate in this study.

\section{AUTHOR CONTRIBUTIONS}

J-PG, PW, and SK conceived and designed the study. LZ and MZ collected and analyzed the data. LZ drafted the manuscript. J-PG, PW, and MZ supported the correction and editing of the manuscript. All authors have read and approved the manuscript.

\section{FUNDING}

This work was supported by the North Rhine-Westphalia State Police (Germany).

\section{ACKNOWLEDGMENTS}

The authors would like to thank Silvia Achtzehn, Eva Engelmeyer, Sanghyeon Ji, Sebastian Keller, Inga Schifferdecker, Veit Schopper, Christian Senfleben, and Aldo Sommer for the excellent organization and support in this project. Special thanks go to the officials of the North Rhine-Westphalia State Police for many years of good collaboration.

\section{SUPPLEMENTARY MATERIAL}

The Supplementary Material for this article can be found online at: https://www.frontiersin.org/articles/10.3389/fspor. 2021.742655/full\#supplementary-material 


\section{REFERENCES}

Anderson, G. S., Plecas, D., and Segger, T. (2001). Police officer physical ability testing - re-validating a selection criterion. Policing 24, 8-31. doi: 10.1108/13639510110382232

Balsalobre-Fernández, C., Tejero-González, C. M., Del Campo-Vecino, J., and Bachero-Mena, B. (2014). Relationships among repeated sprint ability, vertical jump performance and upper-body strength in professional basketball players. Arch. Med. Deporte. 31, 148-153.

Ben Abdelkrim, N., Chaouachi, A., Chamari, K., Chtara, M., and Castagna, C. (2010). Positional role and competitive-level differences in elitelevel men's basketball players. J. Strength Cond. Res. 24, 1346-1355. doi: 10.1519/JSC.0b013e3181cf7510

Bernards, J., Sato, K., Haff, G., and Bazyler, C. (2017). Current research and statistical practices in sport science and a need for change. Sports 5:87. doi: $10.3390 /$ sports5040087

Chaabène, H., Tabben, M., Mkaouer, B., Franchini, E., Negra, Y., Hammami, M., et al. (2015). Amateur boxing: physical and physiological attributes. Sports Med. 45, 337-352. doi: 10.1007/s40279-014-0274-7

Copay, A. G., and Charles, M. T. (2001). The influence of grip strength on handgun marksmanship in basic law enforcement training. Policing 24, 32-39. doi: 10.1108/13639510110382241

Cronin, J., Lawton, T., Harris, N., Kilding, A., and Mcmaster, D. T. (2017). A brief review of handgrip strength and sport performance. J. Strength Cond. Res. 31, 3187-3217. doi: 10.1519/JSC.0000000000002149

Davis, M. R., Easter, R. L., Carlock, J. M., Weiss, L. W., Longo, E. A., Smith, L. M., et al. (2016). Self-reported physical tasks and exercise training in special weapons and tactics (SWAT) teams. J. Strength Cond. Res. 30, 3242-3248. doi: 10.1519/JSC.0000000000001411

Dawes, J. J., Orr, R. M., Flores, R. R., Lockie, R. G., Kornhauser, C., and Holmes, R. (2017). A physical fitness profile of state highway patrol officers by gender and age. Ann. Occup. Environ. Med. 29:16. doi: 10.1186/s40557-017-0173-0

Drid, P., Casals, C., Mekic, A., Radjo, I., Stojanovic, M., and Ostojic, S. M. (2015). Fitness and anthropometric profiles of international vs. national judo medalists in half-heavyweight category. J. Strength Cond. Res. 29, 2115-2121. doi: 10.1519/JSC.0000000000000861

Fernandez-Fernandez, J., Sanz-Rivas, D., Sarabia, J. M., and Moya, M. (2015). Preseason training: the effects of a 17-day high-intensity shock microcycle in elite tennis players. J. Sports Sci. Med. 14, 783-791.

Hamano, S., Ochi, E., Tsuchiya, Y., Muramatsu, E., Suzukawa, K., and Igawa, S. (2015). Relationship between performance test and body composition/physical strength characteristic in sprint canoe and kayak paddlers. Open Access J. Sports Med. 6, 191-199. doi: 10.2147/OAJSM.S82295

Haugen, T., Paulsen, G., Seiler, S., and Sandbakk, O. (2018). New records in human power. Int. J. Sports Physiol. Perform. 13, 678-686. doi: 10.1123/ijspp.2017-0441

Haugen, T., Seiler, S., Sandbakk, Ø., and Tønnessen, E. (2019). The training and development of elite sprint performance: an integration of scientific and best practice literature. Sports Med. 5:44. doi: 10.1186/s40798-019-0221-0

Hedges, L. V., and Olkin, I. (1985). Statistical Methods for Meta-Analysis. Orlando, FL: Academic Press.

Higgins, J. P. T., Li, T., and Deeks, J. J. (2020). "Chapter 6: Choosing effect measures and computing estimates of effect," in Cochrane Handbook for Systematic Reviews of Interventions version 6.1, eds. J. P. T. Higgins, J. Thomas, J. Chandler, M. Cumpston, T. Li, M. Page, and V. Welch (Oxford: Cochrane). p. 143-176.

Hunt, A. P., Orr, R. M., and Billing, D. C. (2013). Developing physical capability standards that are predictive of success on Special Forces selection courses. Mil. Med. 178, 619-624. doi: 10.7205/MILMED-D-1200347

Irving, S., Orr, R., and Pope, R. (2019). Profiling the occupational tasks and physical conditioning of specialist police. Int. J. Exerc. Sci. 12, 173-186.

Kirchengast, S. (2010). Minimum body height requirements for police officers an international comparison. J. Police Sci. Pract. 1, 52-61. doi: 10.7396/IE_ 2011_E

Leischik, R., Foshag, P., Strau,B, M., Littwitz, H., Garg, P., Dworrak, B., et al. (2015). Aerobic capacity, physical activity and metabolic risk factors in firefighters compared with police officers and sedentary clerks. PLOS ONE 10:e0133113. doi: 10.1371/journal.pone.0133113
Lewandowska, J., Buśko, K., Pastuszak, A., and Boguszewska, K. (2011). Somatotype variables related to muscle torque and power in judoists. J. Hum. Kinet. 30, 21-28. doi: 10.2478/v10078-011-0069-y

Loturco, I., Artioli, G. G., Kobal, R., Gil, S., and Franchini, E. (2014). Predicting punching acceleration from selected strength and power variables in elite karate athletes: a multiple regression analysis. J. Strength Cond. Res. 28, 1826-1832. doi: 10.1519/JSC.0000000000000329

Loturco, I., Nakamura, F. Y., Artioli, G. G., Kobal, R., Kitamura, K., Cal Abad, C. C., et al. (2016). Strength and power qualities are highly associated with punching impact in elite amateur boxers. J. Strength Cond. Res. 30, 109-116. doi: 10.1519/JSC.0000000000001075

Mala, J., Szivak, T. K., Flanagan, S. D., Comstock, B. A., Laferrier, J. Z., Maresh, C. M., et al. (2015). The role of strength and power during performance of high intensity military tasks under heavy load carriage. US Army Med. Dep. J. 3-11.

Marins, E., Barbosa, O., Machado, E., Orr, R., Dawes, J., and Del Vecchio, F. (2020). Profile of self-reported physical tasks and physical training in Brazilian special operations units: a web-based cross-sectional study. Int. J. Environ. Res. Public Health 17:7135. doi: 10.3390/ijerph17197135

Marins, E. F., David, G. B., and Del Vecchio, F. B. (2019). Characterization of the physical fitness of police officers: a systematic review. J. Strength Cond. Res. 33, 2860-2874. doi: 10.1519/JSC.0000000000003177

Markovic, G., Jukic, I., Milanovic, D., and Metikos, D. (2007). Effects of sprint and plyometric training on muscle function and athletic performance. J. Strength Cond. Res. 21, 543-549. doi: 10.1519/00124278-20070500000044

Maupin, D., Robinson, J., Wills, T., Irving, S., Schram, B., and Orr, R. (2018). Profiling the metabolic fitness of a special operations police unit. J. Occup. Health 60, 356-360. doi: 10.1539/joh.2018-0029-OA

Ministry of the Interior of North Rhine-Westphalia (2021). Polizei: Einheitliche Mindestgröße von $163 \mathrm{~cm}$ rechtmäßig (Police: uniform minimum height of $163 \mathrm{~cm}$ lawful). Ministry of the Interior of North Rhine-Westphalia. Available online at: https://polizei.nrw/artikel/polizei-einheitliche-mindestgroesse-von163-cm-rechtmaessig (accessed March 05, 2021).

Moreno, M. R., Dulla, J. M., Dawes, J., Orr, R., Cesario, K., and Lockie, R. (2019). Lower-body power and its relationship with body drag velocity in law enforcement recruits. Int. J. Exerc. Sci. 12, 847-858.

Nevill, A. M., Beech, C., Holder, R. L., and Wyon, M. (2010). Scaling concept II rowing ergometer performance for differences in body mass to better reflect rowing in water. Scand. J. Med. Sci. Sports 20, 122-127. doi: 10.1111/j.1600-0838.2008.00874.x

Orr, R., Pope, R., Peterson, S., Hinton, B., and Stierli, M. (2016). Leg power as an indicator of risk of injury or illness in police recruits. Int. J. Environ. Res. Public Health 13: 237. doi: 10.3390/ijerph13020237

Orr, R. M., Caust, E. L., Hinton, B., and Pope, R. (2018). Selecting the best of the best: associations between anthropometric and fitness assessment results and success in police specialist selection. Int. J. Exerc. Sci. 11, 785-796.

Orr, R. M., Stierli, M., Hinton, B., and Steele, M. (2013). "The 30-15 Intermittent Fitness Assessment as a predictor of injury risk in police recruits", in: Tactical Strength and Conditioning Conference. (Melbourne, Australia).

Peña, J., Moreno-Doutres, D., Coma, J., Cook, M., and Buscà, B. (2018). Anthropometric and fitness profile of high-level basketball, handball and volleyball players. Rev. Andaluza Med. Deporte 11, 30-35. doi: 10.1016/j.ramd.2016.03.002

Pryor, R. R., Colburn, D., Crill, M. T., Hostler, D. P., and Suyama, J. (2012). Fitness characteristics of a suburban special weapons and tactics team. J. Strength Cond. Res. 26, 752-757. doi: 10.1519/JSC.0b013e318225f177

Rosenblat, M. A., Perrotta, A. S., and Vicenzino, B. (2019). Polarized vs. threshold training intensity distribution on endurance sport performance: a systematic review and meta-analysis of randomized controlled trials. J. Strength Cond. Res. 33, 3491-3500. doi: 10.1519/JSC.0000000000002618

Santos, D. A., Dawson, J. A., Matias, C. N., Rocha, P. M., Minderico, C. S., Allison, D. B., et al. (2014). Reference values for body composition and anthropometric measurements in athletes. PLoS ONE 9:e97846. doi: 10.1371/journal.pone.0097846

Silk, A., Savage, R., Larsen, B., and Aisbett, B. (2018). Identifying and characterising the physical demands for an Australian specialist policing unit. Appl. Ergon. 68, 197-203. doi: 10.1016/j.apergo.2017.11.012 
Silva, A. F., Clemente, F. M., Lima, R., Nikolaidis, P. T., Rosemann, T., and Knechtle, B. (2019). The effect of plyometric training in volleyball players: a systematic review. Int. J. Environ. Res. Public Health 16:2960. doi: 10.3390/ijerph16162960

Simpson, R. J., Graham, S. M., Connaboy, C., Clement, R., Pollonini, L., and Florida-James, G. D. (2017). Blood lactate thresholds and walking/running economy are determinants of backpack-running performance in trained soldiers. Appl. Ergon. 58, 566-572. doi: 10.1016/j.apergo.2016.04.010

Sperlich, B., Krueger, M., Zinner, C., Achtzehn, S., Marées, M. D., and Mester, J. (2011). Oxygen uptake, velocity at lactate threshold, and running economy in elite special forces. Military Med. 176, 218-221. doi: 10.7205/MILMED-D-10-00234

Strader, J., Schram, B., Irving, S., Robinson, J., and Orr, R. (2020). Special weapons and tactics occupational-specific physical assessments and fitness measures. Int. J. Environ. Res. Public Health 17:8070. doi: 10.3390/ijerph17218070

Tomlin, D. L., and Wenger, H. A. (2001). The relationship between aerobic fitness and recovery from high intensity intermittent exercise. Sports Med. 31, 1-11. doi: 10.2165/00007256-200131010-00001

Tsoukos, A., Drikos, S., Brown, L. E., Sotiropoulos, K., Veligekas, P., and Bogdanis, G. C. (2019). Anthropometric and motor performance variables are decisive factors for the selection of Junior National Female Volleyball Players. J. Human Kinetics 67, 163-173. doi: 10.2478/hukin-2019-0012

Van Der Steeg, G. E., and Takken, T. (2021). Reference values for maximum oxygen uptake relative to body mass in Dutch/Flemish subjects aged 6-65 years: the LowLands Fitness Registry. Euro. J. Appl. Physiol. 121, 1189-1196. doi: 10.1007/s00421-021-04596-6

Vanderburgh, P. M. (2008). Occupational relevance and body mass bias in military physical fitness tests. Med. Sci. Sports Exerc. 40, 1538-1545. doi: 10.1249/MSS.0b013e31817323ee

Wagner, J., Knaier, R., Infanger, D., K, K.O., Klenk, C., Carrard, J., et al. (2021). Novel CPET reference values in healthy adults: associations with physical activity. Med. Sci. Sports Exerc. 53, 26-37. doi: 10.1249/MSS.0000000000002454

Wahl, P., Zwingmann, L., Manunzio, C., Wolf, J., and Bloch, W. (2018). Higher accuracy of the lactate minimum test compared to established threshold concepts to determine maximal lactate steady state in running. Int. J. Sports Med. 39, 541-548. doi: 10.1055/s-0044-102131
Zarić, I., Kukić, F., Jovićević, N., Zarić, M., Marković, M., Toskić, L., et al. (2020). Body height of elite basketball players: do taller basketball teams rank better at the FIBA World Cup? Int. J. Environ. Res. Public Health 17:3141. doi: 10.3390/ijerph17093141

Zwingmann, L., Below, T., Braun, H., Wahl, P., and Goldmann, J. P. (2021a). Consequences of police-related personal protective equipment and physical training status on thermoregulation and exercise energy expenditure. J. Sports Med. Phys. Fitness. doi: 10.23736/S0022-4707.21.1 2196-6. [Epub ahead of print].

Zwingmann, L., Hoppstock, M., Goldmann, J. P., and Wahl, P. (2021b). The effect of physical training modality on exercise performance with police-related personal protective equipment. Appl. Ergon. 93:103371. doi: 10.1016/j.apergo.2021.103371

Zwingmann, L., Strutt, S., Martin, A., Volmary, P., Bloch, W., and Wahl, P. (2019). Modifications of the Dmax method in comparison to the maximal lactate steady state in young male athletes. Phys. Sportsmed. 47, 174-181. doi: $10.1080 / 00913847.2018 .1546103$

Conflict of Interest: The authors declare that the research was conducted in the absence of any commercial or financial relationships that could be construed as a potential conflict of interest.

Publisher's Note: All claims expressed in this article are solely those of the authors and do not necessarily represent those of their affiliated organizations, or those of the publisher, the editors and the reviewers. Any product that may be evaluated in this article, or claim that may be made by its manufacturer, is not guaranteed or endorsed by the publisher.

Copyright (c) 2021 Zwingmann, Zedler, Kurzner, Wahl and Goldmann. This is an open-access article distributed under the terms of the Creative Commons Attribution License (CC BY). The use, distribution or reproduction in other forums is permitted, provided the original author(s) and the copyright owner(s) are credited and that the original publication in this journal is cited, in accordance with accepted academic practice. No use, distribution or reproduction is permitted which does not comply with these terms. 